AUDIT UPDATE

\title{
British Thoracic Society national pleural procedures audit 2010
}

\author{
Clare Hooper, Nick Maskell, on behalf of the BTS audit team
}

\begin{abstract}
- Additional appendices (WA1-5) are published online only. To view these files please visit the journal online (http:// thorax.bmj.com).
\end{abstract}

Received 23 February 2011 Accepted 4 March 2011 Published Online First 7 April 2011

\begin{abstract}
In this report, we detail the results of the 2010 BTS national pleural procedures audit, to which 58 hospitals covering a collective population of more than 20 million patients contributed data regarding local pleural procedure practice and training policies and the process and complications associated with a total of 824 chest drain insertions. The results highlight a promising increase in the use of real time ultrasound guidance for pleural procedures but also deficiencies in pre-procedure consent practice and a significant rate of avoidable minor complications such as drain fall-out and procedure related pain. Action points for improvement to local pleural procedure practice are suggested.
\end{abstract}

\section{BACKGROUND}

Recent reports of complications associated with chest drain insertion in the UK have contributed to a sea change in opinion regarding the management of pleural disease. ${ }^{12}$ This national audit, which in the greatest part relates to chest drain insertion practice, was carried out prior to the publication of the 2010 British Thoracic Society (BTS) pleural disease guidelines. ${ }^{3}$ It was conducted with the key objective of establishing current practice and policies regarding chest drain insertion in the UK with an emphasis on complication rates, level of respiratory team involvement in patient care, use of thoracic ultrasound, frequency of out of hours $(\mathrm{OOH})$ procedures and the training of junior doctors.

\section{AUDIT DESIGN}

The audit was open to all hospitals in the UK.

The 2-month audit period ran from 1 June to 31 July 2010 with a further 10-week period for data entry to the online BTS audit tool system.

Three sections gathered data regarding (1) local policies for pleural procedures, thoracic ultrasound and chest drain insertion training; (2) burden of pleural disease cases and procedures; and (3) detailed records for all chest drain insertions performed for medical patients.

Prospective case identification with retrospective data entry was encouraged.

\section{RESULTS}

Fifty-eight hospitals, covering a collective patient population of $>20$ million, contributed adequate data for inclusion (Supplementary appendix WA 1). The minority of participating respiratory departments had a specialist pleural service, with 12
(20\%) running a dedicated pleural clinic, 11 (19\%) having access to onsite thoracic surgery and 18 (31\%) delivering physician-led thoracoscopy.

\section{Chest drain insertions}

Of 867 records submitted, 824 fulfilled inclusion criteria (585 drains for pleural effusion and 239 for pneumothorax)

Eighty per cent of drains were inserted by the Seldinger technique and $83 \%$ for those where size was documented were of small bore (6-14F).

- Procedure consent. Consent was taken for 549 $(67 \%)$; written in 271 (33\%) and verbal in 278 (35\%). There was no documented evidence of consent in 257 (31\%) and no data entered for 18 (2\%). Drain insertion for pneumothorax appears to be associated with less reliable consent practice; written in only $24 \%$ and no evidence of consent at all in $40 \%$ of procedures in this series.

- Location and timing. The patient bedside remains the most common location for chest drain insertion (48\%) overall, although drains for pneumothorax were most often placed in the Emergency Department (41\%). While most drains overall were inserted within daytime working hours, $36 \%$ for pneumothorax were placed $\mathrm{OOH}$ (Supplementary appendix WA 2).

- Complications (table 1). The most serious possible complications were rare in this series, with no instances of organ trauma and one death (mechanism unclear). Patient-reported pain was common both during (4.1\%) and following $(18 \%)$ drain insertion, and is significantly more frequent with drains placed for pneumothorax (Fisher exact test $\mathrm{p}<0.01)$. When drains fell out (7.3\%), 22/60 (37\%) patients underwent another drain insertion and a further $3 / 42$ effusion patients had pleurodesis deferred until fluid re-accumulation. A drain blockage rate of $8.5 \%$ among pleural effusions was associated with regular flushing in only 110/585 (19\%) of drains and $42 / 101$ (42\%) of drains for pleural infection.

- Specialist care. A total of $62 \%$ patients were nursed on specialist respiratory wards. The medical respiratory team was involved with inpatient management of $78 \%$ of patients and $80 \%$ were reviewed by a respiratory consultant during their admission. A member of the respiratory team performed or supervised drain insertion in 423/824 (51\%) cases overall but only in $90 / 239$ (38\%) of drains for pneumothorax.

- Drains for pneumothorax. A total of 102 drains were placed for secondary spontaneous 
Table 1 Complications of chest drain insertion

\begin{tabular}{|c|c|c|c|}
\hline & $\begin{array}{l}\text { All drains } \\
(n=824)\end{array}$ & $\begin{array}{l}\text { Drains for } \\
\text { pneumothorax } \\
(n=239)\end{array}$ & $\begin{array}{l}\text { Drains for } \\
\text { pleural effusion } \\
(n=585)\end{array}$ \\
\hline \multicolumn{4}{|l|}{ Immediate complications } \\
\hline Bleeding & $11(1.3 \%)$ & $3(1.3 \%)$ & $8(1.4 \%)$ \\
\hline Pain & $34(4.1 \%)$ & $17(7.1 \%)$ & $17(2.9 \%)$ \\
\hline Vasovagal syncope & $17(2.1 \%)$ & $5(2.1 \%)$ & $12(2.0 \%)$ \\
\hline Organ puncture & 0 & 0 & 0 \\
\hline $\begin{array}{l}\text { Failure to place drain in } \\
\text { pleural space }\end{array}$ & $20(2.4 \%)$ & $9(3.8 \%)$ & $11(1.8 \%)$ \\
\hline latrogenic pneumothorax & NA & NA & $22(3.7 \%)$ \\
\hline Death & 0 & 0 & 0 \\
\hline \multicolumn{4}{|l|}{ Delayed complications } \\
\hline Drain fell out & $60(7.3 \%)$ & $19(8 \%)$ & $41(7 \%)$ \\
\hline Pain & $148(18 \%)$ & $59(25 \%)$ & $89(9.7 \%)$ \\
\hline Drain blocked & $61(7.4 \%)$ & $11(4.6 \%)$ & $50(8.5 \%)$ \\
\hline Pleural space infection & $6(0.73 \%)$ & $3(1.3 \%)$ & $3(0.51 \%)$ \\
\hline Skin infection & $7(0.8 \%)$ & $2(0.8 \%)$ & $5(0.9 \%)$ \\
\hline Surgical emphysema & $28(3.4 \%)$ & $24(10 \%)$ & $4(0.7 \%)$ \\
\hline $\begin{array}{l}\text { Re-expansion pulmonary } \\
\text { oedema }\end{array}$ & $3(0.36 \%)$ & 0 & $3(0.4 \%)$ \\
\hline Death & $1(0.12 \%)$ & $1(0.4 \%)$ & 0 \\
\hline
\end{tabular}

pneumothorax (SSP) in patients with median age 71 (range 20-90) years, 88 for primary spontaneous pneumothorax (PSP) (median age 32 (16-87) years) and 47 for traumatic or iatrogenic pneumothorax. There was a failure to attempt aspiration before drain placement in 37/88 (42\%) PSPs, and an inappropriate attempt at aspirating SSPs had been made in $13 / 102(13 \%)$ of cases (Supplementary appendix WA 3). For the small $(<2 \mathrm{~cm})$ pneumothorax cases in this chest drain series $(41 / 239(17 \%))$, conservative management may have been appropriate and preferable.

- Drains for pleural effusions. Patients had a median age of 71 (18-97) years. A total of $41 \%$ patients had an undiagnosed effusion, 34\% malignant effusion and 18\% pleural infection. Of patients drained for pleural malignancy, 96/201 (48\%) underwent talc pleurodesis.

\section{Thoracic ultrasound}

A majority of respiratory departments had at least one ultrasound machine (45/58 (77\%)). In 34 of 58 departments at least one member of the respiratory team was trained to level 1 competence (Supplementary appendix WA 4) with 27 departments having $\geq 1$ consultant and 25 departments having $\geq 1$ trainee who has been formally accredited in thoracic ultrasound.

There was appropriate real-time ultrasound guidance for $52 \%$ of procedures. The remote X-marks the spot approach (carrying no advantage over a blind procedure and potentially

\section{Action points}

Reduce number of avoidable drains inserted, particularly in patients with new or undiagnosed pleural effusions and small or primary pneumothorax.

- Written consent should be taken for all drain insertions.

- Address common complications of procedure-related pain and drain fall out rate with emphasis on optimum insertion and fixation techniques within formal training programmes.

- Aim for all drains for fluid to be placed with real-time ultrasound guidance, avoiding the remote $\mathrm{X}$ marks the spot technique.

being falsely reassuring) was employed for $17 \%$ of drains for fluid (Supplementary appendix WA 5).

\section{Chest drain insertion training}

Formal training in chest drain insertion (didactic lectures and/or simulated practice sessions) is available to F2-ST2 trainees in $44 / 58(76 \%)$ participating hospitals. A smaller proportion offer training to ST3+/SPR level trainees $(21 / 58$ (36\%)).

\section{CONCLUSION}

These results reflect significant scope for improvement in preprocedure consent practice, rate of 'minor' complications relating to poor drain insertion technique and excessive use of chest drains for patients with undiagnosed effusions and small or primary pneumothorax where initial aspiration may have been preferable. Adherence to guidelines, consent practice and incidence of procedure-related pain are inferior for drains placed for pneumothorax which are more likely to be inserted $\mathrm{OOH}$, in the Emergency Department and without respiratory team input. There is a promising trend towards the use of real-time ultrasound guidance for drains placed for fluid, with many physicians training in the imaging technique.

Acknowledgements With thanks to the BTS audit team (Sally Welham, Chris Routh and Dr. Christine Bucknall) for their work on this project.

Competing interests None.

Provenance and peer review Not commissioned; internally peer reviewed.

\section{REFERENCES}

1. National Patient Safety Agency. Risks Associated With the Insertion of Chest Drains. UK: National patient safety agency, 2008. http://www.nrls.npsa.nhs.uk/ resources/?entryid45 $=59887$. NPSA/2008/RRR03.

2. Harris A, O'Driscoll BR, Turkington PM. Survey of major complications of intercostal chest drain insertion in the UK. Postgrad Med J 2010;86:68-72.

3. Havelock T, Teoh R, Laws D, et al. Pleural procedures and thoracic ultrasound: British Thoracic Society pleural disease guideline 2010. Thorax 2010;65(Suppl 2): ii61-76. 